s://www.ilo.org/global/topics/safety-and-health-at-work/areasofwork/hazardous-work/WCMS_110305/lang--en/index.htm

3. Harriss-White B. Waste, social order, and physical disorder in smalltown India. J Dev Stud. 2020 Feb 1[cited 2020 Aug 29];56(2):239-58. Available from: https://www.tandfonline.com/doi/abs/ 10.1080/00220388.2019.1577386

4. Kumar SS. No more stinking tanneries in Bholakpur. Telangana Today 2016 December 25 [cited 2020 July 28]. Available from: https:// telanganatoday.com/stinking-tanneries-bholakpur

5. Chandrachud A. Secularism and the Citizenship Amendment Act. Rochester, NY: Social Science Research Network; 2020 Jan [cited $2020 \mathrm{Jul}$ 28]. Report No: ID 3513828. Available from: https:// papers.ssrn.com/abstract $=3513828$

6. Indian Council of Medical Research. National ethical guidelines for biomedical and health research involving human participants. New Delhi: ICMR; 2017

\title{
COMMENTARY
}

\section{Intention, perception and trust: comment on "Challenges of informed consent during a political crisis" by Mishra and Gaitonde}

\author{
SRIVATSAN R
}

\begin{abstract}
This note explores the relevance of the ethics requirement of having a "study-independent observer/impartial witness" signing off on the informed consent procedure when the community under study is unwilling to do so. It shows how the community's distrust of the researcher as an agent of a malevolent government (expressed in a refusal to sign the consent form) is reflected in the researcher's objective links to government through education and advanced academic research. The note argues that research ethics, rather than blindly following rules, means thinking about context. It reverses the question of relevance of the ethics protocol, to questioning the relevance of the research to the community. It suggests that thinking this through will clarify the position of the researcher and contribute to research ethics
\end{abstract}

Keywords: Informed consent, impartial witness, public health research ethics, Citizenship Amendment Act, National Register of Citizens.

Sapna Mishra and Rakhal Gaitonde have posed (1) an ethical challenge in the political context of their research with a marginalised community, broadly summarised below:

Author: Srivatsan R (r.srivats@gmail.com), formerly Senior Fellow, Anveshi Research Centre for Women's Studies, Hyderabad, India

To cite: Srivatsan R. Intention, perception and trust: comment on "Challenges of informed consent during a political crisis" by Mishra and Gaitonde. Indian J Med Ethics. 2021 Jul-Sep; 6(3)NS: 248-250. DOI: 10.20529/ IJME.2021.052

C Indian Journal of Medical Ethics 2021
How relevant is the research ethics requirement of a "study independent impartial observer" signing off the gathering of informed consent, when insecure Muslim participants distrust the researcher as an agent of an illintentioned government in the context of the Citizenship Amendment Act (CAA) and National Register of Citizens (NRC) of India? ${ }^{1}$

The relevant definition in the Indian Council of Medical Research (ICMR) research guidelines (2) is:

Impartial Witness: 'literate person, who is independent of the research and would not be unfairly influenced by people involved with the study, who attends the informed consent process if the participant and/or their LAR (Legally Acceptable Representative) cannot read and understand the informed consent form and any other written information supplied to the participant. (emphasis mine)' (2: p 155)

\section{The participants' viewpoint}

We approach this question of relevance of having a studyindependent, impartial witness from a different perspective: ie., aligned to the targeted community which sees the researcher as a representative of a malevolent State. Why should the community trust a witness chosen by an untrusted researcher? From this perspective, the authors' question of relevance posed in relation to the impartial witness translates to the more fundamental one: Why is the researcher perceived with suspicion by the community, and further, what is the relevance of her work to them?

For the community members, the researcher working in a government institution is a representative of the State. Their own relationship to the State is one of fear, avoidance and 
caution. Even this fragile relationship had collapsed with the promulgation of the CAA and proposal to establish the NRC, which together threatened to convert their status from being exploited while being despised and ignored, to being hunted, incarcerated, and deported. That the researchers were part of government implied that they were untrustworthy. And yet, the community members were not entirely distrustful, because they were willing (albeit reluctantly) to participate in the study - they only did not want to sign a document. In other words, they suspected that the consent signature could be used against them.

If the e-waste-picking community were ambivalent towards the researcher, this seems to reflect the ambiguity around the figure of the researcher: Who exactly does the researcher represent and what does research in general want to achieve?

\section{State and research agendas}

On the one hand, social science research in India has been steeped in State agendas from colonial times. Colonial research on groups was part of the administrative attempt to know and rule Indian populations: in other words, to isolate, control and govern them (3). In the post-Independence period, the Indian Council of Social Science Research was created to advise on development planning and represent India on the academic platform of advanced nations(4). Studies of marginalised castes, tribes, communities usually have the same goals: a) development and policy inputs; and b) participation in international research (5). To this day, most traditional $\mathrm{PhD}$ theses require a list of policy recommendations at the end of the work. We are able to conduct any research at all because we are supported by the State's system of advanced education which governs verifiability, impartiality and objectivity, through rules, protocols and guidelines. Without these norms, research would have limited academic value.

Thus, academic research of marginal communities has a perspective and goals framed by the State. Often, such a perspective tuned to broad national utility, ie, the greatest good of the greatest number (or the national interest), has no patience for the everyday problems faced by the community (like an employer who may fire the e-waste picker for wasting time with the researcher, or that the charge of being polluters may be a threat to the legality of their work). A researcher who imbibes this broadly statist, abstract view of their goal will treat the requirement of an impartial witness as a mechanical formality. The authors, however, problematise the choice of the impartial witness, and flag the ethical question in their note: Who should such a witness be if she were to be relevant?

\section{The ethics of health research}

On the other hand, medical practice and research have a history of critical reflection of their relationship to marginalised subjects. This reflection becomes the discipline of bioethics (6) in which the principles of autonomy, beneficence, non-maleficence and justice are developed (7). Informed consent is a crucial dimension of autonomy.

The ethical supervision of getting consent is supposed to be neutral, ie, not biased towards the researcher, and hence the need for an impartial witness while obtaining informed consent when the participants are not literate and may not easily understand complex outcomes of the research. This perspective is spelt out in the ICMR Guidelines cited above, where the witness signs off on the process during which a community being researched agrees either in signature or thumb impression to give their consent. The required presence of the witness during the whole process (rather than simply for the signing ceremony) implies a concern that the researcher may play fast and loose with the informed consent procedure. When the ICMR specifies this safety net, it means that the state too has begun to think of the needs of the marginalised. Note that this development of the state's ethical consciousness occurs in the administrative context of a bioethics of medical research. The irony is that another aspect of the same State has promulgated the CAA and is proposing the NRC - there is a split between the ethical dimension of the state and its immediate politics of Hindutva.

\section{Discussion}

[N]o one is ever an abstract moral agent... There is no way to answer the question: 'Which moral rules ought I to respect in this situation?' until I have first answered the question: 'Who am I and what is my concrete relationship to the other people involved in this situation?'

Alasdair Maclntyre, "What has ethics to learn from medical ethics?" (8: p 47)

There is a long history of debate on whether applied ethics, and more narrowly bioethics, can be a mechanical "application" of pre-decided rules: the argument is that the intelligent use of principles would be the heart of the ethical project (8). Further, reasoned use is indicated since bioethical principles may not have anticipated the anthropological context in which they have to be used in the case studied here, and more so, its volatile context (9). This would not mean that the guidelines are invalid; they may, with careful thought, serve as effective guardrails against the potential for misuse of the research. In other words, bioethics may point the way for research ethics in general.

It would be impossible to apply abstract rules to this unstable research situation without doing a grave injustice to the research participants from the community. The research ethics committee's responsibility is thus, to address the question of what will meet the principles of autonomy, beneficence, non-maleficence and distributive justice in this situation. The question posed by the researcher is a challenge to the ethics committee to debate and actively engage with the dilemma presented by the case: Who can be 
an impartial witness to ensure these principles are followed?

In turn, the community's response is a challenge to the researcher: because of the impasse it forces, it makes her demonstrate to the community her respect for autonomy, beneficence, non-maleficence and justice. This would mean inverting the question asked by the researcher regarding the relevance of an impartial witness what is the relevance, potential and end of this research project to this marginalised community? And demonstrating this responsibility to the community may need a "study independent individual" as witness to be a committed observer who is independent of the project: ie, perhaps another responsible researcher or local activist who is unconnected to the project, who is familiar with and committed to the perspectives of the marginalised and can convince them of the benefit of the project. Indeed, the ICMR Guidelines permit such an interpretation. Since they must be seen as guidelines for reflection, and not rules for application, the ethics committee may, after deliberation, explicitly sanction the proxy signature or consent of the witness, in place of that of the community, if they continue to hesitate to sign. Such a decision would remove the feared risk of misuse of their signatures.

The project can only be defended to the community by demonstrating that it aims to do good, has taken active steps to avoid consequential harm, and is just when seen from their point of view. Such a demonstration of intentions cannot succeed by following abstract rules; it will require the work of ethics to be done on the ground, and in earnest. Ultimately, I believe, that addressing such a challenge will transform the critical position of the researcher with respect to the State's perspective; and sharpen the selfunderstanding of research and its relation to the State's infrastructure which supports it. Doubtless, such a selfunderstanding in the context of the current split consciousness (between the ethical guidelines of ICMR and the politics of (AA/NRC) of the State will be as much ethical as political (10). That will have unpredictable consequences.

Acknowledgment: I would like to express my gratitude to the copy-editor who has strengthened this essay and made it more readable.

'Note: The Citizenship (Amendment) Act, 2019 spearheaded by the ruling Bharatiya Janata Party offered Indian citizenship to persecuted religious minorities from Afghanistan, Bangladesh and Pakistan who are Hindus, Sikhs, Buddhists, Jains, Parsis or Christians (but not to Muslims) who arrived in India before the end of December 2014. This is the first Indian law that discriminates based on religion. It has caused immense political concern regarding oppression of minorities (especially when used in conjunction with the National Register of Citizens, see below) in India and has led to widespread protests by secularists and Muslims alike across the country.

The National Register of Citizens is a government-maintained register of all Indian citizens. It was mandated by the 2003 amendment of the Citizenship Act of 1955. Its purpose is to document legal citizens and thus facilitate the deportation of illegal immigrants (who are not in the register). Given the history of administrative inefficiency, political vendetta and Hindutva's malevolence towards Muslims, it is certain that many marginalised Muslim residents in India in informal occupations and precarious lives will simply not be included in the register, thus making them vulnerable to incarceration in detention camps and ultimately deportation. The vow of the BJP government to bring this register into operation immediately after the Citizenship (Amendment) Act (see above) has caused alarm and protests across the country against what has been understood as two prongs of a broad ethnic cleansing programme.

\section{References}

1. Mishra S, Gaitonde R. Challenges of informed consent during a political crisis: A case study of research with a marginalised group. Indian J. Med Ethics. Published online on December 19, 2020.DOI: 10.20529/IJME.2020.130.

2. Indian Council of Medical Research. National Ethical Guidelines for Biomedical and Health Research Involving Human Participants, New Delhi: ICMR, 2017[cited 2021 Feb 14]. Available from: https:// main.icmr.nic.in/sites/default/files/guidelines

ICMR_Ethical_Guidelines_2017.pdf

3. Srivatsan R. Native Noses and Nationalist Zoos: Debates in Colonial and Early Nationalist Anthropology of Castes and Tribes. Econ Pol Wkly. 2005 Jan; 40(19):1986-98.

4. Indian Council of Social Science Research. Memorandum of Association and Rules. New Delhi: ICSSR; amended 2014[cited 2021 Feb 14]. Available from: https://icssr.org/sites/default/files/ moaicssr.pdf

5. Indian Council of Social Science Research. Social Sciences in India Retrospective and Prospective - A Report, Vol 1 The Indian Council of Social Science Research Review Committee;1973 [cited 2021 Feb 14]. Available from: https://archive.org/stream/dli.csl. 330/330_djvu.txt

6. Stanford Encyclopedia of Philosophy. Theory and Bioethics. 2020 Nov 25 [cited 2021 Feb 10]. Available from: https:// plato.stanford.edu/entries/theory-bioethics/

7. Beauchamp TL, Childress JF. Principles of Biomedical Ethics (4th ed). Oxford: Oxford University Press, 1984.

8. Maclntyre A. What has ethics to learn from medical ethics? Philos Exch. 1978 Summer[cited 2021 Feb 14]; 9(1):37-47. Available from: https://digitalcommons.brockport.edu/cgi/viewcontent.cgi? article $=1206 \&$ context $=$ phil_ex

9. Marshall PA. Anthropology and Bioethics. Med Anthropol Q. New Series. 1992 Mar[cited 2021 Feb 14];6(1): 49-73. Available from: http://www.jstor.org/stable/648742

10. Hull G. The Subject and Power of Bioethics. Journal of Ethics, Medicine and Public Health. 2017 Jul 19[cited 2021 Feb 14]. Available from: https://papers.ssrn.com/sol3/papers.cfm? abstract_id=3002513 